\title{
Correlates of nicotine dependence among adolescent waterpipe smokers
}

\author{
Raed Bahelah ${ }^{\mathrm{a}, \mathrm{g}}$, Joseph R. DiFranza ${ }^{\mathrm{b}}$, Kenneth D. Ward ${ }^{\mathrm{c}, \mathrm{d}}$, Fouad M. Fouad ${ }^{\mathrm{c}, \mathrm{e}}$, Thomas \\ Eissenberg $^{f}$, Ziyad Ben Taleb ${ }^{\mathrm{a}}$, Rana Jaber ${ }^{\mathrm{a}}$, Olatokunbo Osibogun ${ }^{\mathrm{a}}$, and Wasim Maziak ${ }^{\mathrm{a}, \mathrm{c}}$ \\ aDepartment of Epidemiology, Robert Stempel College of Public Health \& Social Work, Florida \\ International University, Miami, FL, USA \\ bepartment of Family Medicine and Community Health, University of Massachusetts Medical \\ School, Worcester, MA, USA \\ 'Syrian Center for Tobacco Studies, Aleppo, Syria \\ dUniversity of Memphis School of Public Health, Memphis, TN, USA

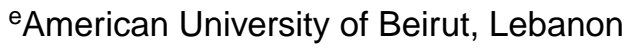 \\ fDepartment of Psychology and Center for the Study of Tobacco Products, Virginia \\ Commonwealth University, Richmond, VA, USA \\ gFaculty of Medicine and Health Sciences, Aden University, Yemen
}

\begin{abstract}
Introduction-Waterpipe smoking is addictive and its use is increasing globally among youth, yet little is known about the factors associated with nicotine dependence (ND) among waterpipe smokers. We investigated the factors associated with ND symptoms among a sample of Lebanese adolescents who smoke a waterpipe.
\end{abstract}

Methods-We collected data on factors potentially associated with ND (individual, sociodemographic, environmental, smoking patterns) among 160 current (past 30 days) waterpipe smokers recruited from $8^{\text {th }}$ and $9^{\text {th }}$ school grades in Lebanon. We assessed the loss of autonomy over tobacco using the Hooked on Nicotine Checklist (HONC), ND using the International Classification of Diseases, $10^{\text {th }}$ revision (ICD-10), and the number of ND symptoms endorsed.

\footnotetext{
Corresponding author: Raed Bahelah, Department of Epidemiology, Robert Stempel College of Public Health and Social Work, Florida International University, 11200 SW 8th Street, Miami, FL 33199, rbahe002@ fiu.edu.

Publisher's Disclaimer: This is a PDF file of an unedited manuscript that has been accepted for publication. As a service to our customers we are providing this early version of the manuscript. The manuscript will undergo copyediting, typesetting, and review of the resulting proof before it is published in its final citable form. Please note that during the production process errors may be discovered which could affect the content, and all legal disclaimers that apply to the journal pertain.

Contributors

RB and WM conceptualized and designed the study; RB analyzed the data; FMF obtained the data; RB and JRD prepared the first draft; all authors contributed to the interpretation of the data, critically revised the manuscript for important intellectual content, and approved the final manuscript as submitted.

Conflict of Interest

The authors declare that they have no conflict of interest.
} 
Results-Depressive symptoms, lower self-esteem, and having at least one sibling who smokes a waterpipe were associated with the presence of ND symptoms, while enrollment in public schools, smoking a waterpipe $\geq 30$ minutes per session, and believing that cigarette smoking is harmful to health were associated with endorsement of a higher number of ND symptoms. Smoking a whole waterpipe head without sharing and being in $9^{\text {th }}$ grade in this study were associated with the presence and endorsement of a higher number of ND symptoms.

Conclusions-We identified specific social and psychological characteristics, waterpipe smoking patterns, and beliefs about harmful effects of smoking associated with the presence of ND among adolescent waterpipe smokers. Considering these factors when planning policies to prevent ND among waterpipe smokers is warranted.

\section{Keywords}

Waterpipe; Lebanon; Nicotine Dependence; Adolescents; Loss of Autonomy

\section{INTRODUCTION}

Use of a waterpipe (narghile, shisha, hookah) has re-emerged in the global epidemic of tobacco smoking (Maziak et al., 2015). It is associated with adverse health outcomes such as impaired lung function, lung and esophageal cancers (Montazeri et al., 2015), coronary artery disease (Akl et al., 2010; El-Zaatari et al., 2015), and nicotine dependence (ND; Aboaziza and Eissenberg, 2015; Maziak, 2014; Maziak et al., 2004). In many Eastern Mediterranean countries, where waterpipe use is traditional, it has surpassed cigarettes as the most common tobacco use method among 13-15 year-old schoolchildren (Maziak et al., 2015; WHO, 2015). Alarmingly, tobacco smoking using a waterpipe is increasing among youth in other parts of the world where it is not traditional. For example, current (past 30 days) waterpipe tobacco smoking among US high school students has increased to the extent that its prevalence was similar to that of cigarette smoking ( $9.4 \%$ vs. $9.2 \%$, respectively) by 2014 (Arrazola et al., 2015). Furthermore, many young waterpipe smokers are cigarettenaïve and at higher risk for initiation of cigarette smoking (Jaber et al., 2015a; Soneji et al., 2015). This waterpipe-to-cigarette transition may signal the appearance of ND among waterpipe smokers who may find a craving for nicotine easier to satisfy using the easily accessible cigarette as compared to the stationary, less accessible waterpipe (Jaber et al., 2015a). Thus, preventing ND among waterpipe smokers is an integral component for the overall success of tobacco control efforts worldwide.

Many youth are attracted to the social aspects of a waterpipe and perceive it as a fashionable, safer alternative to cigarettes with a lower potential for addiction (Akl et al., 2013). Contrary to this misperception, a growing body of research shows that waterpipe smokers are exposed to significant amounts of nicotine and experience symptoms of ND similar to those among cigarette smokers such as drug seeking behavior, loss of control over waterpipe use, and difficulty quitting (Aboaziza and Eissenberg, 2015; Ward et al., 2005; Eissenberg and Shihadeh, 2009; Maziak et al., 2011). Moreover, evidence from the few studies that examined ND among adult waterpipe smokers found that a higher frequency of waterpipe use (proxy of ND) was associated with self-perception of being hooked on a waterpipe and behavioral adaptations to support access to a waterpipe including carrying/owning a 
waterpipe, and smoking mainly alone and at home (Maziak et al., 2004; Ward et al., 2007). Other studies that applied modified versions of the Lebanon Waterpipe Dependence Scale found that factors such as daily use, Arab ethnicity, age of initiation, length of smoking session, number of waterpipes owned, average sessions per week, and average waterpipe heads used per session were risk factors for ND among waterpipe smokers (Primack et al., 2014; Kassim et al., 2014). However, some of these studies relied on participants' selfperception of being addicted to a waterpipe (Maziak et al., 2004; Ward et al., 2007), while others applied ND measures that may not be sensitive to ND symptoms at low levels of tobacco use (Primack et al., 2014; Kassim et al., 2014), and no study so far has examined the factors associated with ND among adolescent waterpipe smokers.

In the first report from the Waterpipe Dependence among Lebanese Youth (WDLY) study, we described the early symptoms of ND among adolescent waterpipe smokers and showed that ND symptoms can be experienced earlier among waterpipe smokers than cigarette smokers (Bahelah et al., 2016). Building on that work, the current study aims to identify factors associated with ND among adolescent waterpipe smokers using baseline data from the WDLY. Such knowledge is important to identify youth at a higher risk of becoming addicted to a waterpipe and who can potentially benefit from early prevention and intervention strategies.

\section{METHODS}

\subsection{Participants and procedures}

The WDLY is a cohort study of 498 adolescent smokers and non-smokers (mean \pm SD age at baseline for the whole sample $=14.1 \pm 1.1$ years) enrolled in $8^{\text {th }}$ and $9^{\text {th }}$ school grades from 4 regions in Lebanon (Beirut, Mount Lebanon, Nabatiye, South Lebanon; Figure 1). Details about the study design and procedures can be found elsewhere (Bahelah et al., 2016). Briefly, among 178 schools with $8^{\text {th }}$ and $9^{\text {th }}$ grades from these 4 regions, 38 schools agreed to participate and provided private rooms on schools' premises to insure confidentiality of interviews. A brief, in-classroom, self-administered survey was distributed to all students who provided parental consents and their assent in order to determine eligibility. For smokers, those who smoked a waterpipe or cigarettes, but not both, at least once during the past 30 days were eligible to participate. Because this report focuses on the factors associated with ND, only those who reported smoking a waterpipe at baseline $(\mathrm{N}=160)$ were included in the analysis.

Data on waterpipe use patterns (Maziak et al., 2004, 2005; Primack et al., 2014), attitudes towards a waterpipe (Hammal et al., 2008; Maziak et al., 2004; Ward et al., 2005), and the factors associated with ND among adolescent smokers (Kleinjan et al., 2012; DiFranza et al., 2007a; Racicot et al., 2013; O'Loughlin et al., 2002) were obtained using a pilot-tested, interviewer-administered questionnaire. The questionnaire was translated into Arabic, and back translated to English for comparison and fine-tuning using standard methods (Brislin, 1970). Four techniques were used to improve recall of past events: decomposition, bounded recall, personal landmarks, and the depiction of these landmarks visually to create a personal calendar for each student (DiFranza et al., 2007b, 2009). Students provided personal landmarks (e.g., birthday, entry into school) which were depicted on a calendar for each 
student to aid in recalling past events such as dates of smoking milestones (initiation of waterpipe smoking, smoking a whole waterpipe head without sharing) and appearance of ND symptoms. The study protocol was approved by the institutional review boards of Florida International University and the American University of Beirut.

\subsection{Measures}

2.2.1 Explanatory variables-The selection of the factors potentially associated with ND among adolescent waterpipe smokers was guided by the literature on ND among adolescent smokers and waterpipe-specific use patterns. A description of these variables follows.

1. Smoking-related factors. Smoking milestones, average time spent during a waterpipe smoking session ( $<30$ minutes, $30-60$ minutes, $>60$ minutes), past month smoking frequency (did not smoke a waterpipe in the past 30 days, smoked less than once a week, smoked at least once a week but not every day, smoked every day/almost every day), and quantity (number of waterpipes smoked in the past 30 days) were obtained. Students were also asked whether they had experienced any of several reactions the first time they inhaled from a waterpipe (felt relaxed, felt high/buzz sensation, experienced burning throat/bad taste). Beliefs and attitudes towards a waterpipe were evaluated by asking students if they believe waterpipe smokers look more attractive than nonsmokers, have more friends, if waterpipe smoking makes a person lose weight, and if waterpipe smoking is harmful to health (Jaber et al., 2015b)

2. Socio-demographics and environmental factors. Socio-demographics include age, gender, school type (public, private), regular physical activity (at least once per week), school grade $\left(8^{\text {th }}, 9^{\text {th }}\right)$, and years of education for each parent. Environmental factors include smoking by parents, siblings, close friends, and exposure to pro-tobacco advertisements (Kleinjan et al., 2012).

3. Psychological characteristics associated with ND among youth were also measured (DiFranza et al., 2007a; Racicot et al., 2013; O'Loughlin et al., 2009).

1. Stress during the past 6 months was measured by a list of 15 life events that represent common stressors for adolescents (e.g., body weight, parental divorce; Racicot et al., 2013; O'Loughlin et al., 2009). Students rated their stress level to each item on a four-point Likert scale (Not at all to A whole lot) with a total score of $0-45$; higher scores indicate higher stress. Cronbach's alpha for the stress scale in this study was 0.79 .

2. Depressive symptoms during the past 6 months were measured using a six-item Depressive Symptom Scale (DSS) on a four-point Likert scale (Never to Often; Brunet et al., 2014), with a total score of 0-18. Higher score indicates more depressive symptoms. Cronbach's alpha for the DSS in this study was 0.75 . 
3. Novelty seeking was measured using nine items from Cloninger's Personality Questionnaire (DiFranza et al., 2007a) on a five-point Likert scale (Not at all true to Very true) with 0-36 total score. Higher score indicates higher novelty. Cronbach's alpha for the novelty seeking scale in this study was 0.76 .

4. Impulsivity was measured using seven items on a five-point Likert scale (Not at all true to Very true) with 0-28 total score (DiFranza et al., 2007a), and higher score indicates higher impulsivity. Cronbach's alpha for the impulsivity scale in this study was 0.81 .

5. Distractibility was measured using six items on a five-point Likert scale (Never to Always) with 0-24 total score (DiFranza et al., 2007a). Higher score indicates higher distractibility. Cronbach's alpha for the distractibility scale in this study was 0.63 .

6. Self-esteem was measured using a ten-item Rosenberg's Self-Esteem Scale assessed on a four-point Likert scale (Strongly Disagree to Strongly Agree), with total score of 0-30 (Waters et al., 2006). Higher score indicates higher self-esteem. Cronbach's alpha for the self-esteem scale in this study was 0.79 .

2.2.2 Outcome variables-Table 1 shows the 19 survey items used to measure the three outcomes in this study: the loss of autonomy, ND, and the number of ND items endorsed. Each item represents a symptom of ND and was validated among adolescent smokers in previous studies (DiFranza et al., 2007a; O'Loughlin et al., 2002). Each item has Yes/No response option and a "Yes" response indicates endorsement of that item.

Smokers lose autonomy over tobacco when quitting requires an effort or involves discomfort. The loss of autonomy is an early indicator of developing ND (DiFranza et al., 2007a, 2002), and can be measured using a 10-item Hooked on Nicotine Checklist (HONC). Endorsement of at least $1 \mathrm{HONC}$ item indicates a loss of autonomy. $\mathrm{HONC}$ is a validated, sensitive indicator of symptoms of ND presenting with infrequent tobacco use (DiFranza et al., 2002; Wheeler et al., 2004). HONC scores are computed by summing the number of symptoms endorsed (range 0-10) and its scores correlate with addiction-related changes in neural structures of smoker's brain (Huang et al., 2013).

ND was measured using the WHO's International Classification of Diseases - Tenth Revision (ICD-10). ICD-10 consists of 6 criteria of ND and endorsement of at least 3 of these criteria over a 12-month period is required for the diagnosis of ICD-10 ND (DiFranza et al., 2007a; O'Loughlin et al., 2002). Finally, we used the number of ND items endorsed (from a total of 19 items shown in Table 1) as a proxy measure of the level of ND among adolescent waterpipe smokers, in which a higher number of endorsed items indicates an advanced level of ND (Apelberg et al., 2014; Caraballo et al., 2009).

Both the HONC and ICD-10 have shown acceptable internal consistency among waterpipe smokers in this cohort (Bahelah et al., 2016). We further tested the correlation among the HONC, ICD-10, and the number of ND items endorsed in this study. The third measure 
(number of ND items endorsed) has an average inter-item correlation of 0.14 and an acceptable internal consistency as shown by Cronbach' alpha of 0.76 in this study.

\subsection{Data analysis}

Summary statistics were presented for categorical variables using frequencies/percentages, and mean \pm standard deviation (SD) for continuous variables. At the bivariate level, associations among categorical variables were tested using chi-squared or Fisher Exact tests, while t-test (when normality was met) or Mann-Whitney $U /$ Kruskal-Wallis tests (when normality was violated) were used to test group differences in continuous variables. We assessed the magnitude of association between the number of ND items endorsed with ICD-10 and HONC separately using point-biserial Pearson correlation coefficient, while the magnitude of association between ICD-10 and HONC was assessed using Phi correlation coefficient.

All explanatory variables (smoking-related, socio-demographics, environmental, psychological characteristics) significant at $\mathrm{p}<0.15$ in the bivariate models were entered into separate multivariable logistic regression models to identify the factors associated with the loss of autonomy ( $0=\mathrm{No}, 1=\mathrm{Yes})$, and ICD-10 ND ( $0=\mathrm{No}, 1=$ Yes) (Bursac et al., 2008). Odds ratios (OR) with $95 \%$ confidence intervals (CI) were reported from these models. As the third outcome (number of ND items endorsed) in this study is a count variable, multivariable Poisson regression model was used to identify the factors associated with this outcome, and regression parameters (b) with 95\% CI were reported from this model (Coxe et al., 2009). We accounted for over-dispersion in the Poisson regression model and adjusted the standard errors of regression parameters by using "scale=Pearson" option in SAS 9.3 (SAS Institute Inc., NC; USA) (Lee et al., 2012). Age at baseline and gender were included in all models. We checked for multicollinearity among explanatory variables using the variance inflation factor (VIF). All VIF values were less than 5 indicating multicollinearity did not affect our models (Nazar et al., 2015). All tests were two-tailed and the statistical significance was set at $\mathrm{p}<0.05$.

\section{RESULTS}

\subsection{Sample characteristics}

The sample for this study consisted of 160 current (past 30 days) waterpipe smokers, of whom $56.8 \%$ were girls. Overall, $71.2 \%$ endorsed $\geq 1$ HONC item (i.e., lost autonomy), and $38.1 \%$ met ICD-10 criteria for ND (endorsed $\geq 3$ criteria). Table 1 presents the percentage of participants who endorsed each item of ND used in this study.

\subsection{Correlation among measures of nicotine dependence}

All measures of ND were positively correlated with one another. The number of ND items endorsed correlated significantly with ICD-10 ND (Point-biserial coefficient $=0.74, p<0.001$ ) and HONC (Point-biserial coefficient $=0.61, \mathrm{p}<0.001$ ), while both ICD-10 ND and HONC correlated well with one another (Phi coefficient $=0.42, \mathrm{p}<0.001$ ). 


\subsection{Results from bivariate analyses}

Table 2 presents bivariate associations between the explanatory variables and the 3 studied outcomes: loss of autonomy, ND, and number of ND items endorsed. There were no significant gender differences in the loss of autonomy ( $\mathrm{p}=0.44)$, ND $(\mathrm{p}=0.91)$, or number of $\mathrm{ND}$ items endorsed $(\mathrm{p}=0.92)$. Although a higher proportion of participants who lost autonomy came from public schools ( $\mathrm{p}=0.01$ ), school type was not associated with either $\mathrm{ND}(\mathrm{p}=0.15)$ or number of ND items endorsed $(\mathrm{p}=0.08)$. School grade was associated with $\mathrm{ND}(\mathrm{p}=0.02)$, number of ND items endorsed ( $\mathrm{p}=0.01)$, but not with loss of autonomy $(\mathrm{p}=0.08)$. Those who lost autonomy had higher mean levels for stress, depression, distractibility, novelty seeking, impulsivity, and a lower mean score on self-esteem than those who did not lose autonomy (all p-values $<0.05$ ). Number of ND items endorsed was positively associated with depression, distractibility, and novelty-seeking (all p-values $<0.05$ ). Waterpipe smoking by at least one parent or at least one sibling was associated with $\mathrm{ND}(\mathrm{p}=0.01)$, while having a favorite waterpipe advertisement was associated with the loss of autonomy ( $\mathrm{p}=0.01)$ and number of ND items endorsed $(\mathrm{p}=0.002)$. Believing that waterpipe smokers look more attractive and have more friends were positively associated with ND and number of ND items endorsed, while believing that waterpipe smoking is harmful to health was negatively associated with number of ND items endorsed (all p-values $<0.05)$. Smoking a whole waterpipe head without sharing, past month smoking frequency and number of waterpipes smoked, and average time during waterpipe smoking session were all associated with loss of autonomy, ND, and number of ND items endorsed (all p-values $<0.05$; Table 2).

\subsection{Results from multivariable analyses}

Table 3 shows the results of separate multivariable logistic regression models for the factors associated with loss of autonomy and ND, and table 4 shows the results of a multivariable Poisson regression model for the factors associated with the number of ND items endorsed. Covariates included in all models were: age at baseline, gender, past month smoking quantity and frequency, age of smoking initiation, and the average time spent during a smoking session.

Factors associated with the loss of autonomy were enrollment in public schools $(\mathrm{OR}=2.8$, $95 \% \mathrm{CI}=1.1-7.5, \mathrm{p}=0.03)$, regular physical activity $(\mathrm{OR}=8.6,95 \% \mathrm{CI}=2.6-28.3$, $\mathrm{p}<0.001)$, depression $(\mathrm{OR}=1.2,95 \% \mathrm{CI}=1.1-1.3, \mathrm{p}=0.02)$, smoking a whole waterpipe head without sharing $(\mathrm{OR}=5.8,95 \% \mathrm{CI}=1.6-21.1, \mathrm{p}<0.007)$, smoking a waterpipe for 30-60 minutes $(\mathrm{OR}=3.6,95 \% \mathrm{CI}=1.1-11.8, \mathrm{p}=0.03)$ or $>60$ minutes $(\mathrm{OR}=7.1,95 \% \mathrm{CI}=1.4-$ 34.7, $\mathrm{p}=0.01)$, and self-esteem $(\mathrm{OR}=0.8,95 \% \mathrm{CI}=0.7-0.9, \mathrm{p}=0.03)$.

Ninth graders were more likely than eight graders to be $\mathrm{ND}$ ( $\mathrm{OR}=2.6,95 \% \mathrm{CI}=1.2-5.9$, $\mathrm{p}=0.02)$. Other correlates of ND included having at least one sibling who smokes a waterpipe $(\mathrm{OR}=2.5,95 \% \mathrm{CI}=1.1-6.1, \mathrm{p}=0.04)$, and smoking a whole waterpipe head without sharing $(\mathrm{OR}=4.6,95 \% \mathrm{CI}=2.0-10.7, \mathrm{p}<0.001)$.

Endorsement of a higher number of ND symptoms was associated with enrollment in public schools $(b=0.22,95 \% \mathrm{CI}=0.01-0.44, \mathrm{p}=0.04)$, being in $9^{\text {th }}$ grade $(b=0.31,95 \% \mathrm{CI}=0.09$ - 
0.53, $\mathrm{p}=0.005)$, smoking a whole waterpipe head without sharing $(b=0.49,95 \% \mathrm{CI}=0.26-$ $0.72, \mathrm{p}<0.0001)$, smoking a waterpipe for $30-60$ minutes $(b=0.30,95 \% \mathrm{CI}=0.02-0.57$, $\mathrm{p}=0.03)$ or $>60$ minutes $(b=0.36,95 \% \mathrm{CI}=0.05-0.68, \mathrm{p}=0.02)$, and believing that cigarette smoking is harmful to health $(b=0.28,95 \% \mathrm{CI}=0.02-0.54, \mathrm{p}=0.03)$.

Generally, parameter estimates obtained from a Poisson regression reflect the change in the log-count of the outcome variable for a 1 unit change in the predictor, holding all other explanatory variables in the model constant (Hilbe, 2014). For example, attending public schools increases the log-count of endorsed ND symptoms by 0.22 compared to private schools, holding all other variables constant. All other parameter estimates from Poisson regression in this study can be interpreted in the same way.

\section{DISCUSSION}

This is the first study to examine the factors associated with ND among adolescent waterpipe smokers using validated measures. Our results show that specific psychological characteristics (depressive symptoms, lower self-esteem), waterpipe-related use patterns (e.g., smoking a whole waterpipe head without sharing), believing that cigarette smoking is harmful to health, enrollment in public schools, and having at least one sibling who smokes a waterpipe were associated with ND among waterpipe smokers. Furthermore, this study highlights two modifiable factors uniquely associated with ND among adolescent waterpipe smokers: believing that cigarette smoking is harmful to health and longer smoking sessions of a waterpipe. Collectively, these findings provide novel insights into the characteristics of young waterpipe smokers more likely to become addicted to a waterpipe and identify specific areas that can be targeted for preventing ND among waterpipe smokers. Incorporating educational materials on tobacco-related harm and addiction in school curricula, targeting those enrolled in public schools, and addressing waterpipe use by family members are strategies that can be implemented to prevent ND among young waterpipe smokers.

The co-existence of certain psychological characteristics and symptoms of ND among adolescent cigarette smokers has been well characterized (Kleinjan et al., 2012; DiFranza et al., 2007a; Racicot et al., 2013). In this study, we identified two such factors - depression and self-esteem - that were associated with the loss of autonomy among adolescent waterpipe smokers. Generally, self-esteem is an important psychological characteristic that can distinguish adolescent smokers from non-smokers (Guillon et al., 2007). Given the high prevalence of waterpipe use among youth in Lebanon and other Middle Eastern countries coupled with its prominent social aspect, adolescents with lower self-esteem may smoke a waterpipe as a means to cope with their personal discontent and can get easily hooked on a waterpipe. In fact, low self-esteem was a predictor of current (past 30 days) waterpipe smoking among a sample of male adolescents from Iran (mean age $=16.7$ years; Karimy et al., 2013). Moreover; adolescents with low self-esteem usually have low refusal self-efficacy skills, which, in turn, predicts higher frequency of waterpipe use among adolescents (Jaber et al., 2015b) and the appearance of ND. 
Previous studies among adolescent cigarette smokers show that smokers report more depressive symptoms than nonsmokers (Goodman and Capitman, 2000), and depressive symptoms predict progression to regular smoking (Karp et al., 2006), and ND (DiFranza et al., 2007a). In this study, adolescents with depressive symptoms have a higher risk of experiencing ND symptoms. It is likely that adolescents with depression symptoms smoke a waterpipe to alleviate the negative affective experiences associated with these symptoms. In fact, dealing with depressive symptoms was reported as one of the main motives for smoking a waterpipe among Middle Eastern youth (Akl et al., 2013). The relationship between depression and ND symptoms may arise as a result of a repeated exposure to a waterpipe (i.e., self-medication) to cope with depressive symptoms which results in physiological adaptations that lead to the appearance of ND (Pomerleau, 1995). On the other hand, genetic and environmental factors common to both depression and ND symptoms were also proposed as the link between these two conditions (DiFranza et al., 2007a)

In Lebanon and other Middle Eastern countries, many young people view a waterpipe as a symbol of cultural identity and smoke it for the first time with a family member (Afifi et al., 2013; Asfar et al., 2005). Specifically, previous studies among Middle Eastern youth showed that having a sibling who smokes a waterpipe was a predictor of initiation (McKelvey et al., 2014) and higher use (Jaber et al., 2015b) of a waterpipe. In line with these findings, waterpipe smokers in this study who have at least one sibling who smokes a waterpipe were twice as likely to become addicted to a waterpipe. As explained by the social learning model of ND among adolescent cigarette smokers, imitation and social reinforcement (e.g., positive attitudes toward smoking) delineate the influence of siblings' smoking on ND among adolescents (Hu et al., 2011). Moreover, findings from studies among adolescent cigarette smokers have shown that cigarette smoking among siblings can facilitate access to and continued use of cigarettes (Kandel et al., 2007; Doubeni et al., 2010), which determine the appearance of ND among adolescents (Kandel et al., 2007; Doubeni et al., 2010). These same theories can be applied to explain a higher risk of ND among adolescent waterpipe smokers who have at least one sibling who smokes a waterpipe. Another interesting finding in this study is that enrollment in public schools, as compared to private schools, was associated with loss of autonomy and endorsement of a higher number of ND symptoms. This can be due to less tolerance to smoking in private schools that may enforce stricter rules against smoking by students and school personnel, which has been shown to prevent waterpipe smoking progression among a cohort of schoolchildren in Jordan (median age $\approx 13$ years at baseline; Jaber et al., 2015b).

The global resurgence of waterpipe use among youth can be attributed to a mistaken belief that a waterpipe is less health-damaging and addictive than cigarettes (Maziak, 2014; Maziak et al., 2015; WHO, 2015). The predominantly intermittent smoking patterns of a waterpipe and a presumed "filtering" effect of its smoke when it passes through a water bowl are the main drivers for this wrong belief (Maziak et al., 2015; Maziak, 2014; WHO, 2015). Of note, believing that a waterpipe is less harmful and addictive than cigarettes was a predictor of current waterpipe use among youth (Sutfin et al., 2011; Eissenberg et al., 2008; Alzyoud et al., 2013). This study shows that adolescent waterpipe smokers who believed that cigarette smoking is harmful to health were more likely to endorse a higher number of ND symptoms. Although not statistically significant, adolescents in this study who do not 
believe that a waterpipe is harmful to health were more likely to endorse more ND symptoms ( $\mathrm{p}=0.32$, data not shown). This finding is consistent with results from a cohort study of Canadian young waterpipe smokers $(\mathrm{N}=777$, mean age $=20$ years at baseline), which found that those who smoke cigarettes infrequently were more likely to sustain waterpipe use 4 years later (Dugas et al., 2014). The lower harm perception of waterpipe tobacco smoking compared to cigarettes can lead to sustained use of a waterpipe (Dugas et al., 2014) and endorsement of higher number of ND symptoms among young waterpipe smokers. This wrong perception is augmented, at a population level, by the societal acceptability of waterpipe use among youth, marketing strategies, and the lack of effective regulatory policies to prevent its use among youth.

Physical activity has been shown to protect against cigarette smoking in youth (Ali et al., 2015). Contrary to this observation, youth who were physically active were more likely to report smoking a waterpipe than those who were not physically active (Primack et al., 2010). Moreover, higher physical activity was a predictor of initiation (McKelvey et al., 2014) and progression (Jaber et al., 2015b) on waterpipe smoking among a cohort of schoolchildren in Jordan (median age $\approx 13$ years at baseline). In line with these findings, our study shows that youth who are physically active are more likely to loss autonomy over waterpipe smoking. It is possible that youth who perform regular physical activity underestimate the harmful effects of a waterpipe and are attracted to the social nature common to both waterpipe use and physical activity (McKelvey et al., 2014).

This study highlights the importance of intensity and smoking patterns of waterpipe users in the appearance of ND symptoms among adolescents. Smoking a whole waterpipe head without sharing was the only factor associated with all 3 outcomes of this study (loss of autonomy, ND, number of ND items endorsed). Interestingly, the association between the duration of a smoking session and the number of ND items endorsed was stronger for sessions that last over 60 minutes than those lasting 30-60 minutes, possibly reflecting a dose-response relationship. Longer smoking sessions expose smokers to higher doses of nicotine and this greater nicotine exposure can be associated with endorsement of a higher number of ND symptoms. Findings from previous studies documented a positive correlation between the duration of a waterpipe smoking session and the boost in plasma nicotine (the difference between pre-smoking and post-smoking nicotine plasma concentration) (Maziak et al., 2011; Eissenberg and Shihadeh, 2009). In addition, the number of puffs on a waterpipe, which is greater during longer smoking sessions, correlate positively with the maximal plasma nicotine concentration in waterpipe smokers (Jacob et al., 2011). However, it is also possible that more addicted smokers require more nicotine resulting in longer smoking sessions which will be further investigated in our longitudinal study. One last observation is that the number of waterpipes smoked in the past 30 days was not associated with the presence of ND among waterpipe smokers in this study. As tolerance to nicotine develops over time, adolescent waterpipe smokers may need to smoke greater number of waterpipes in order to achieve pleasurable effects and avoid withdrawal symptoms.

Limitations of this study include the possibility of recall errors of past events. To minimize this limitation, we employed four recall assistance methods to improve the recall of past events (DiFranza et al., 2007b, 2009). Another limitation is that some explanatory variables 
did not reach statistical significance perhaps as a result of a relatively small sample size.

However, inclusion of the explanatory variables in our models was informed by a review of the important factors associated with ND among adolescent smokers (Kleinjan et al., 2012; DiFranza et al., 2007a; Racicot et al., 2013). In addition, our ongoing study will have more power to detect significant differences as the sample size of youth who use a waterpipe increases. Making causal inferences is limited by the cross-sectional nature of the study. Finally, our results may not be generalizable to adolescent waterpipe smokers from other countries and there is a need for additional research elsewhere (e.g., the U.S.) to continue to build this important body of knowledge. Despite these limitations, this exploratory study represents the first attempt to examine the factors associated with the presence of ND among adolescent waterpipe smokers.

This study demonstrates that certain sociodemographic characteristics (public vs. private school attendance, being in $9^{\text {th }}$ grade), psychological characteristics (depression and selfesteem), exposure to siblings' waterpipe use, and greater use of a waterpipe (e.g., smoking a whole waterpipe head without sharing, longer duration of smoking sessions) are associated with ND symptomatology among adolescent waterpipe smokers. Therefore, waterpipe prevention and intervention strategies may have greatest impact by educating youth about the harmful and addictive properties of a waterpipe, teaching them positive coping skills, targeting those enrolled in public schools, and addressing waterpipe use by family members.

\section{Acknowledgments}

The authors wish to thank Dr. Stefany Coxe, Assistant Professor of Psychology- Florida International University, and Dr. Boubakari Ibrahimou, Assistant Professor of Biostatistics-Florida International University, for their helpful comments on the statistical analysis of this manuscript.

\section{Role of Funding Sources}

This work was supported by the National Institute on Drug Abuse of the National Institutes of Health [Grant number R01 DA035160; PI: Wasim Maziak]. Dr. Eissenberg's effort was supported, in part, by the National Institute on Drug Abuse of the National Institutes of Health under Award Number P50DA036105 and the Center for Tobacco Products of the U.S. Food and Drug Administration. The content is solely the responsibility of the authors and does not necessarily represent the views of the NIH or the FDA. Dr. Rana Jaber was a post-doctoral fellow with Dr. Purnima Madhivanan who received a grant from Merck \& Co.

\section{References}

Aboaziza E, Eissenberg T. Waterpipe tobacco smoking: what is the evidence that it supports nicotine/ tobacco dependence? Tob Control. 2015; 24(Suppl .1):i44-i53. [PubMed: 25492935]

Afifi R, Khalil J, Fouad F, Hammal F, Jarallah Y, Abu Farhat H, Ayad M, Nakkash R. Social norms and attitudes linked to waterpipe use in the Eastern Mediterranean Region. Soc Sci Med. 2013; 98:125134. DOI: 10.1016/j.socscimed.2013.09.007 [PubMed: 24331890]

Akl EA, Gaddam S, Gunukula SK, Honeine R, Jaoude PA, Irani J. The effects of waterpipe tobacco smoking on health outcomes: a systematic review. Int J Epidemiol. 2010; 39:834-857. [PubMed: 20207606]

Akl EA, Jawad M, Lam WY, Co CN, Obeid R, Irani J. Motives, beliefs and attitudes towards waterpipe tobacco smoking: a systematic review. Harm Reduct J. 2013; 10:12.doi: 10.1186/1477-7517-10-12 [PubMed: 23816366]

Alzyoud S, Weglicki LS, Kheirallah KA, Haddad L, Alhawamdeh KA. Waterpipe smoking among middle and high school Jordanian students: patterns and predictors. Int J Environ Res Public Health. 2013; 10:7068-7082. DOI: 10.3390/ijerph10127068 [PubMed: 24351734] 
Ali MM, Amialchuk A, Heller LR. The influence of physical activity on cigarette smoking among adolescents: evidence from Add Health. Nicotine Tob Res. 2015; 17:539-545. [PubMed: 25187062]

Apelberg BJ, Corey CG, Hoffman AC, Schroeder MJ, Husten CG, Caraballo RS, Backinger CL. Symptoms of tobacco dependence among middle and high school tobacco users: results from the 2012 National Youth Tobacco Survey. Am J Prev Med. 2014; 47(2 Suppl. 1):S4-14. DOI: 10.1016/ j.amepre.2014.04.013 [PubMed: 25044195]

Arrazola RA, Singh T, Corey CG, Husten CG, Neff LJ, Apelberg BJ, Bunnell RE, Choiniere CJ, King BA, Cox S, McAfee T, Caraballo RS, Centers for Disease Control Prevention (CDC). Tobacco use among middle and high school students - United States, 2011-2014. MMWR. 2015; 64:381-385. [PubMed: 25879896]

Asfar T, Ward KD, Eissenberg T, Maziak W. Comparison of patterns of use, beliefs, and attitudes related to waterpipe between beginning and established smokers. BMC Public Health. 2005; 5:19. [PubMed: 15733316]

Bahelah R, DiFranza JR, Fouad FM, Ward KD, Eissenberg T, Maziak W. Early symptoms of nicotine dependence among adolescent waterpipe smokers. Tob Control. 2016; In press. doi: 10.1136/ tobaccocontrol-2015-052809

Brislin RW. Back-translation for cross-cultural research. J Cross Cult Psychol. 1970; 1:185-216.

Brunet J, Sabiston CM, Chaiton M, et al. Measurement invariance of the depressive symptoms scale during adolescence. BMC Psychiatry. 2014; 14:95.doi: 10.1186/1471-244X-14-95 [PubMed: 24679136]

Bursac Z, Gauss CH, Williams DK, Hosmer DW. Purposeful selection of variables in logistic regression. Source Code Biol Med. 2008; 3:17.doi: 10.1186/1751-0473-3-17 [PubMed: 19087314]

Caraballo RS, Novak SP, Asman K. Linking quantity and frequency profiles of cigarette smoking to the presence of nicotine dependence symptoms among adolescent smokers: findings from the 2004 National Youth Tobacco Survey. Nicotine Tob Res. 2009; 11:49-57. DOI: 10.1093/ntr/ntn008 [PubMed: 19246441]

Coxe S, West SG, Aiken LS. The analysis of count data: a gentle introduction to poisson regression and its alternatives. J Pers Assess. 2009; 91:121-136. DOI: 10.1080/00223890802634175 [PubMed: 19205933]

DiFranza JR, Savageau JA, Fletcher K, et al. Measuring the loss of autonomy over nicotine use in adolescents: the DANDY (Development and Assessment of Nicotine Dependence in Youths) study. Arch Pediatr Adolesc Med. 2002; 156:397-403. [PubMed: 11929376]

DiFranza JR, Savageau JA, Fletcher K, Pbert L, O’Loughlin J, McNeill AD, Ockene JK, Friedman K, Hazelton J, Wood C, Dussault G, Wellman RJ. Susceptibility to nicotine dependence: the Development and Assessment of Nicotine Dependence in Youth 2 study. Pediatrics. 2007a; 120:e974-83. [PubMed: 17908753]

DiFranza J, Savageau J, Fletcher K, O’Loughlin J, Pbert L, Ockene JK, McNeill AD, Hazelton J, Friendman K, Dussault G, Wood C, Wellman RJ. Symptoms of tobacco dependence after brief intermittent use-The Development and Assessment of Nicotine Dependence in Youth-2 Study. Arch Pediatr Adolesc Med. 2007b; 161:704-710. [PubMed: 17606835]

DiFranza JR, Rigotti NA, McNeill AD, Ockene JK, Savageau JA, St Cyr D, Coleman M. Initial symptoms of nicotine dependence in adolescents. Tob Control. 2009; 9:313-319.

Doubeni CA, Reed G, Difranza JR. Early course of nicotine dependence in adolescent smokers. Pediatrics. 2010; 125:1127-1133. DOI: 10.1542/peds.2009-0238 [PubMed: 20439592]

Dugas EN, O’Loughlin EK, Low NC, Wellman RJ, O’Loughlin JL. Sustained waterpipe use among young adults. Nicotine Tob Res. 2014; 16:709-16. DOI: 10.1093/ntr/ntt215 [PubMed: 24379147]

Eissenberg T, Ward KD, Smith-Simone S, Maziak W. Waterpipe tobacco smoking on a U.S. College campus: prevalence and correlates. J Adolesc Health. 2008; 42:526-529. DOI: 10.1016/ j.jadohealth.2007.10.004 [PubMed: 18407049]

Eissenberg T, Shihadeh A. Waterpipe tobacco and cigarette smoking: direct comparison of toxicant exposure. Am J Prev Med. 2009; 37:518-23. [PubMed: 19944918]

El-Zaatari ZM, Chami HA, Zaatari GS. Health effects associated with waterpipe smoking. Tob Control. 2015; 24(Suppl 1):i31-i43. [PubMed: 25661414] 
Goodman E, Capitman J. Depressive symptoms and cigarette smoking among teens. Pediatrics. 2000; 106:748-755. [PubMed: 11015518]

Guillon MS, Crocq MA, Bailey PE. Nicotine dependence and self-esteem in adolescents with mental disorders. Addict Behav. 2007; 32:758-764. DOI: 10.1016/j.addbeh.2006.06.018 [PubMed: 16839692]

Hammal F, Mock J, Ward KD, Eissenberg T, Maziak W. A pleasure among friends: how narghile (waterpipe) smoking differs from cigarette smoking in Syria. Tob Control. 2008; 17:e3.doi: 10.1136/tc.2007.020529 [PubMed: 18375726]

Hilbe, JM. Modeling Count Data. Cambridge University Press; New York, NY: 2014.

Hu MC, Griesler P, Schaffran C, Kandel D. Risk and protective factors for nicotine dependence in adolescence. J Child Psychol Psychiatry. 2011; 52:1063-1072. DOI: 10.1111/j. 1469-7610.2010.02362.x [PubMed: 21250992]

Huang W, DiFranza JR, Kennedy DN, Zhang N, Ziedonis D, Ursprung S, King JA. Progressive levels of physical dependence to tobacco coincide with changes in the anterior cingulum bundle microstructure. PLoS One. 2013; 8:e67837.doi: 10.1371/journal.pone.0067837 [PubMed: 23861816]

Jaber R, Madhivanan P, Veledar E, Khader Y, Mzayek F, Maziak W. Waterpipe a gateway to cigarette smoking initiation among adolescents in Irbid, Jordan: a longitudinal study. Int J Tuberc Lung Dis. 2015a; 19:481-7. [PubMed: 25860006]

Jaber R, Madhivanan P, Khader Y, Mzayek F, Ward KD, Maziak W. Predictors of waterpipe smoking progression among youth in Irbid, Jordan: a longitudinal study (2008-2011). Drug Alcohol Depend. 2015b; 153:265-270. [PubMed: 26024787]

Jacob P 3rd, Abu Raddaha AH, Dempsey D, Havel C, Peng M, Yu L, Benowitz NL. Nicotine, carbon monoxide, and carcinogen exposure after a single use of a water pipe. Cancer Epidemiol Biomarkers Prev. 2011; 20:2345-2353. DOI: 10.1158/1055-9965.EPI-11-0545 [PubMed: 21908725]

Kandel DB, Hu MC, Griesler PC, Schaffran C. On the development of nicotine dependence in adolescence. Drug Alcohol Depend. 2007; 91:26-39. DOI: 10.1016/j.drugalcdep.2007.04.011 [PubMed: 17553635]

Karimy M, Niknami S, Heidarnia AR, Hajizadeh E, Shamsi M. Refusal self efficacy, self esteem, smoking refusal skills and water pipe (Hookah) smoking among Iranian male adolescents. Asian Pac J Cancer Prev. 2013; 14:7283-7288. [PubMed: 24460289]

Karp I, O'Loughlin J, Hanley J, Tyndale RF, Paradis G. Risk factors for tobacco dependence in adolescent smokers. Tob Control. 2006; 15:199-204. [PubMed: 16728750]

Kassim S, Al-Bakri A, Al'Absi M, Croucher R. Waterpipe tobacco dependence in U.K. male adult residents: a cross-sectional study. Nicotine Tob Res. 2014; 16:316-325. DOI: 10.1093/ntr/ntt148 [PubMed: 24130142]

Kleinjan M, Vitaro F, Wanner B, Brug J, Van den Eijnden RJJM, Engels RCME. Predicting nicotine dependence profiles among adolescent smokers: the roles of personal and social-environmental factors in a longitudinal framework. BMC Public Health. 2012; 12:196. [PubMed: 22424115]

Lee JH, Han G, Fulp WJ, Giuliano AR. Analysis of overdispersed count data: application to the Human Papillomavirus Infection in Men (HIM) Study. Epidemiol Infect. 2012; 140:1087-1094. DOI: 10.1017/S095026881100166X [PubMed: 21875452]

Maziak W, Ward KD, Eissenberg T. Factors related to frequency of narghile (waterpipe) use: the first insights on tobacco dependence in narghile users. Drug Alcohol Depend. 2004; 76:101-106. DOI: 10.1016/j.drugalcdep.2004.04.007 [PubMed: 15380294]

Maziak W, Eissenberg T, Ward KD. Patterns of waterpipe use and dependence: implications for intervention development. Pharmacol Biochem Behav. 2005; 80:173-179. DOI: 10.1016/j.pbb. 2004.10.026 [PubMed: 15652393]

Maziak W, Rastam S, Shihadeh AL. Nicotine exposure in daily waterpipe smokers and its relation to puff topography. Addict Behav. 2011; 36:397-399. DOI: 10.1016/j.addbeh.2010.11.013 [PubMed: 21185126]

Maziak W. The waterpipe: a new way of hooking youth on tobacco. Am J Addict. 2014; 23:103-107. [PubMed: 25187045] 
Maziak W, Taleb ZB, Bahelah R, Islam F, Jaber R, Auf R, Salloum RG. The global epidemiology of waterpipe smoking. Tob Control. 2015; 24(Suppl 1):i3-i12. [PubMed: 25298368]

McKelvey K, Attonito J, Madhivanan P, Jaber R, Yi Q, Mzayek F, Maziak W. Determinants of waterpipe smoking initiation among school children in Irbid, Jordan: a 4-year longitudinal analysis. Drug Alcohol Depend. 2014; 142:307-313. DOI: 10.1016/j.drugalcdep.2014.06.038 [PubMed: 25060962]

Montazeri Z, Nyiraneza C, El-Katerji H, Little J. Waterpipe smoking and cancer: systematic review and meta-analysis. Tob3 Control. 2016; pii: tobaccocontrol-2015-052758. Epub ahead of print. doi: 10.1136/tobaccocontrol-2015-052758

Nazar GP, Lee JT, Arora M, Millett C. Socioeconomic inequalities in secondhand smoke exposure at home and at work in 15 low- and middle-income countries. Nicotine Tob Res. 2015; pii: ntv261. doi: $10.1093 / \mathrm{ntr} / \mathrm{ntv} 261$

O’Loughlin J, DiFranza JR, Tarasuk J, Meshefedjian G, McMillan-Davey E, Paradis G, Tyndale RF, Clarke P, Hanley J. Assessment of nicotine dependence symptoms in adolescents: a comparison of five indicators. Tob Control. 2002; 11:354-360. [PubMed: 12432161]

O'Loughlin J, Karp I, Koulis T, Paradis G, Difranza J. Determinants of first puff and daily cigarette smoking in adolescents. Am J Epidemiol. 2009; 170:585-597. DOI: 10.1093/aje/kwp179 [PubMed: 19635735]

Pomerleau OF. Individual differences in sensitivity to nicotine: implications for genetic research on nicotine dependence. Behav Genet. 1995; 25:161-177. DOI: 10.1007/BF02196925 [PubMed: 7733857]

Primack BA, Fertman CI, Rice KR, Adachi-Mejia AM, Fine MJ. Waterpipe and cigarette smoking among college athletes in the United States. J Adolesc Health. 2010; 46:45-51. [PubMed: 20123257]

Primack BA, Khabour OF, Alzoubi KH, et al. The LWDS-10J: reliability and validity of the Lebanon Waterpipe Dependence Scale among university students in Jordan. Nicotine Tob Res. 2014; 16:915-922. DOI: 10.1093/ntr/ntu002 [PubMed: 24571810]

Racicot S, McGrath JJ, Karp I, O’Loughlin J. Predictors of nicotine dependence symptoms among never-smoking adolescents: a longitudinal analysis from the Nicotine Dependence in Teens Study. Drug Alcohol Depend. 2013; 130:38-44. [PubMed: 23195923]

Soneji S, Sargent JD, Tanski SE, Primack BA. Associations between initial water pipe tobacco smoking and snus use and subsequent cigarette smoking: results from a longitudinal study of US adolescents and young adults. JAMA Pediatr. 2015; 169:129-136. DOI: 10.1001/jamapediatrics. 2014.2697 [PubMed: 25485959]

Sutfin EL, McCoy TP, Reboussin BA, Wagoner KG, Spangler J, Wolfson M. Prevalence and correlates of waterpipe tobacco smoking by college students in North Carolina. Drug Alcohol Depend. 2011; 115:131-136. DOI: 10.1016/j.drugalcdep.2011.01.018 [PubMed: 21353750]

Ward KD, Hammal F, VanderWeg MW, Eissenberg T, Asfar T, Rastam S, Maziak W. Are waterpipe users interested in quitting? Nicotine Tob Res. 2005; 7:149-156. [PubMed: 15804687]

Ward KD, Eissenberg T, Gray JN, Srinivas V, Wilson N, Maziak W. Characteristics of U.S. waterpipe users: a preliminary report. Nicotine Tob Res. 2007; 9:1339-1346. [PubMed: 18058352]

Waters K, Harris K, Hall S, Nazir N, Waigandt A. Characteristics of social smoking among college students. J Am Coll Health. 2006; 55:133-139. DOI: 10.3200/JACH.55.3.133-139 [PubMed: 17175899]

Wheeler KC, Fletcher KE, Wellman RJ, Difranza JR. Screening adolescents for nicotine dependence: the Hooked On Nicotine Checklist. J Adolesc Health. 2004; 35:225-230. DOI: 10.1016/ j.jadohealth.2003.10.004 [PubMed: 15313504]

WHO. Health Effects, Research Needs And Recommended Actions For Regulators. WHO Study Group on Tobacco Product Regulation (TobReg); Geneva, Switzerland: 2015. World Health Organization Advisory Note: Waterpipe Tobacco Smoking: 2nd Edition. 


\section{Highlights}

- We studied nicotine dependence (ND) among adolescent waterpipe (WP) smokers

- $\quad$ Having at least 1 sibling smokes WP was associated with ND

- $\quad$ Smoking WP for $\geq 30$ minutes was associated with higher ND symptoms

- Believing that cigarette smoking is harmful was associated with higher ND symptoms

- $\quad$ Smoking a whole WP without sharing was associated with ND and higher ND symptoms 


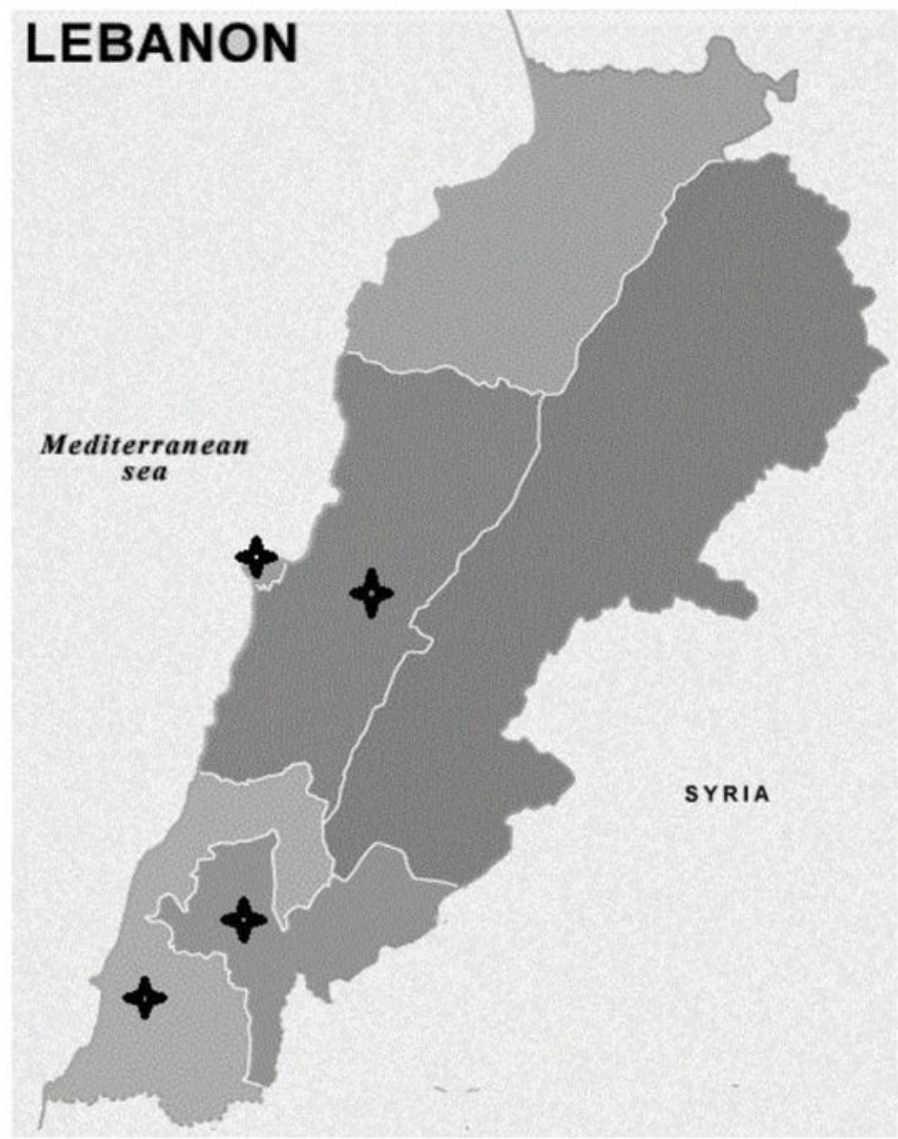

Figure 1.

A map of Lebanon showing the four regions where study participants were recruited from. 


\section{Table 1}

Survey items used to measure loss of autonomy and nicotine dependence among adolescent waterpipe smokers in Lebanon ${ }^{\neq}$

\begin{tabular}{ll}
\hline Item & $\begin{array}{l}\text { Number (\%) of } \\
\text { participants } \\
\text { endorsing this } \\
\text { item }\end{array}$ \\
\hline
\end{tabular}

1. A strong desire or sense of compulsion to use tobacco * (4 items)
a. Have you ever had strong cravings to smoke waterpipe? $\mathscr{l}$
$59(36.9)$
b. Have you ever felt like you were addicted to waterpipe? I
$54(33.8)$
c. Have you ever felt like you really needed a waterpipe? Il
d. Is it hard to keep from smoking waterpipe in places where you are not supposed to, like school? I

2. Difficulties in controlling tobacco-taking behaviour in terms of its onset, termination, or levels of use * (3 items)

$\begin{array}{lll}\text { a. } & \text { Have you ever tried to quit waterpipe smoking but could not do it? } \% \text { t } & 40(25.0) \\ \text { b. } & \text { Do you smoke waterpipe now because it is really hard to quit? } \% \text { t } & 19(11.9) \\ \text { c. } & \text { Are you smoking waterpipe more now than you planned to when you started? } & 72(45.0)\end{array}$

3. A physiological withdrawal state * $(5$ items $)$

When you have tried to stop smoking or when you have not been able to smoke...

a. Did you find it hard to concentrate because you could not smoke waterpipe? $9 /$

b. Did you feel more irritable because you could not smoke waterpipe? $\mathscr{l} \quad 20$ (12.5)

c. Did you feel a strong need or urge to smoke waterpipe? $\mathbb{I}$

d. Did you feel nervous, restless, or anxious because you could not smoke waterpipe? I/ 34 (21.3)

e. Do you smoke waterpipe to avoid withdrawal symptoms? 18 (11.3)

4. Evidence of tolerance ${ }^{*}(2$ items)

a. Do you find that you need to smoke waterpipe more often than you used to? 27 (16.9)

b. Do you have to smoke waterpipe more often now to feel relaxed than you used to? 25 (15.6)

5. Neglect of alternative pleasures * $(4$ items)

a. Do you find that you are spending more of your free time trying to get waterpipe? $53(33.1)$

b. Have you cut down on your physical activities or sports because you smoke waterpipe? 30 (18.8)

c. Do you ever give up going places or doing things because waterpipe smoking is not allowed? 17 (10.6)

d. Have you stopped hanging out with certain friends because you smoke waterpipe? $\quad 4(2.5)$

6. Use despite harm * $(1$ item)

a. Has a doctor or nurse told you that you should quit smoking waterpipe because it was damaging your health?

${ }^{\neq}$These survey items represent the 6 criteria of nicotine dependence based on the International Classification of Diseases- $10^{\text {th }}$ revision and include the 10 items of Hooked on Nicotine Checklist.

The 6 criteria of nicotine dependence based on the International Classification of Diseases, 10-revision (ICD-10). Endorsement of any 1 item in a criterion (any 2 items in criterion 3) represents endorsement of that criterion, and the presence of $\geq 3$ criteria over a 12-month period is needed for the diagnosis of nicotine dependence.

II The 10 items of Hooked on Nicotine Checklist (HONC). Endorsement of any HONC item indicates that a smoker has lost autonomy over tobacco use.

Drug Alcohol Depend. Author manuscript; available in PMC 2017 November 01. 


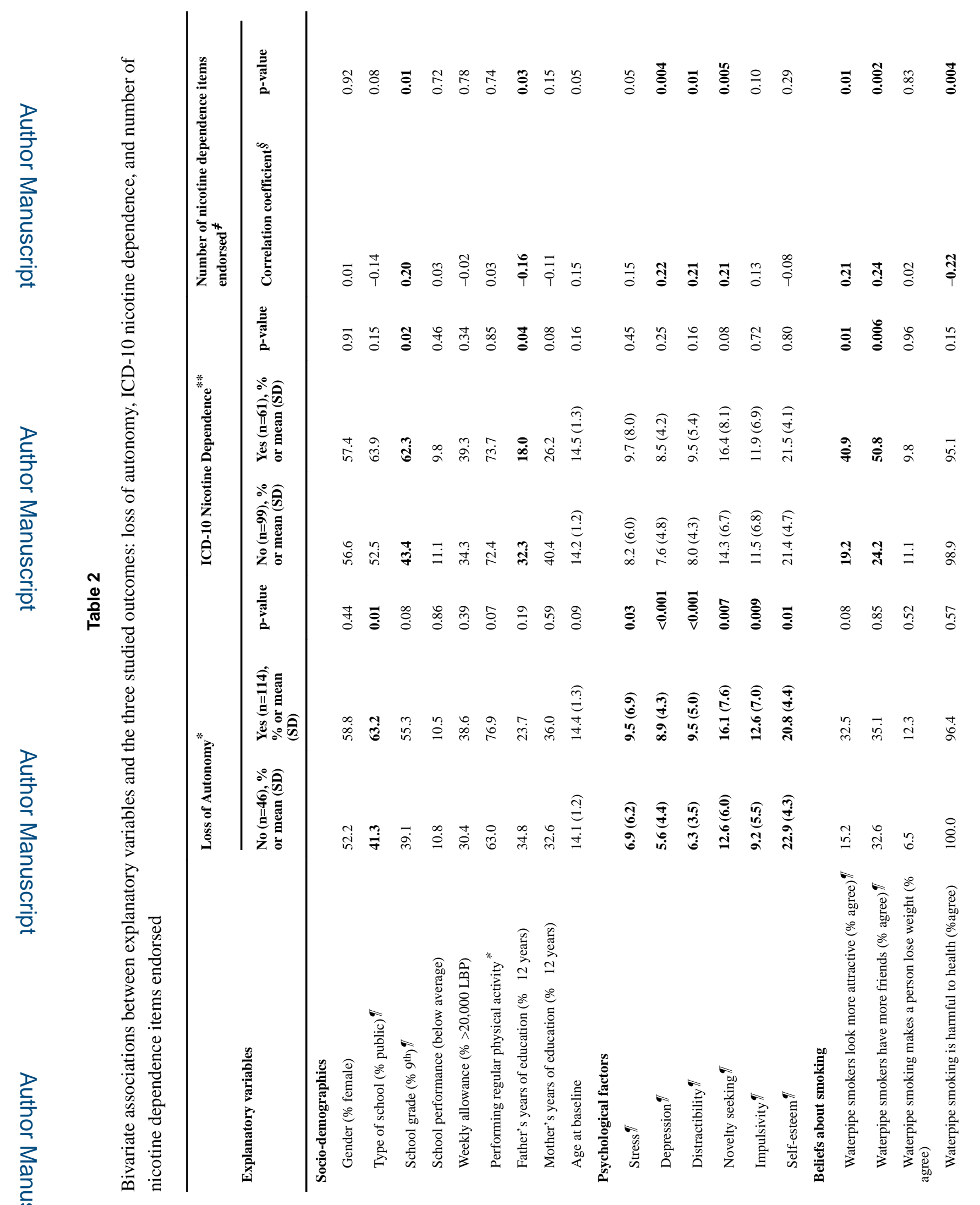

Drug Alcohol Depend. Author manuscript; available in PMC 2017 November 01. 
Bahelah et al.

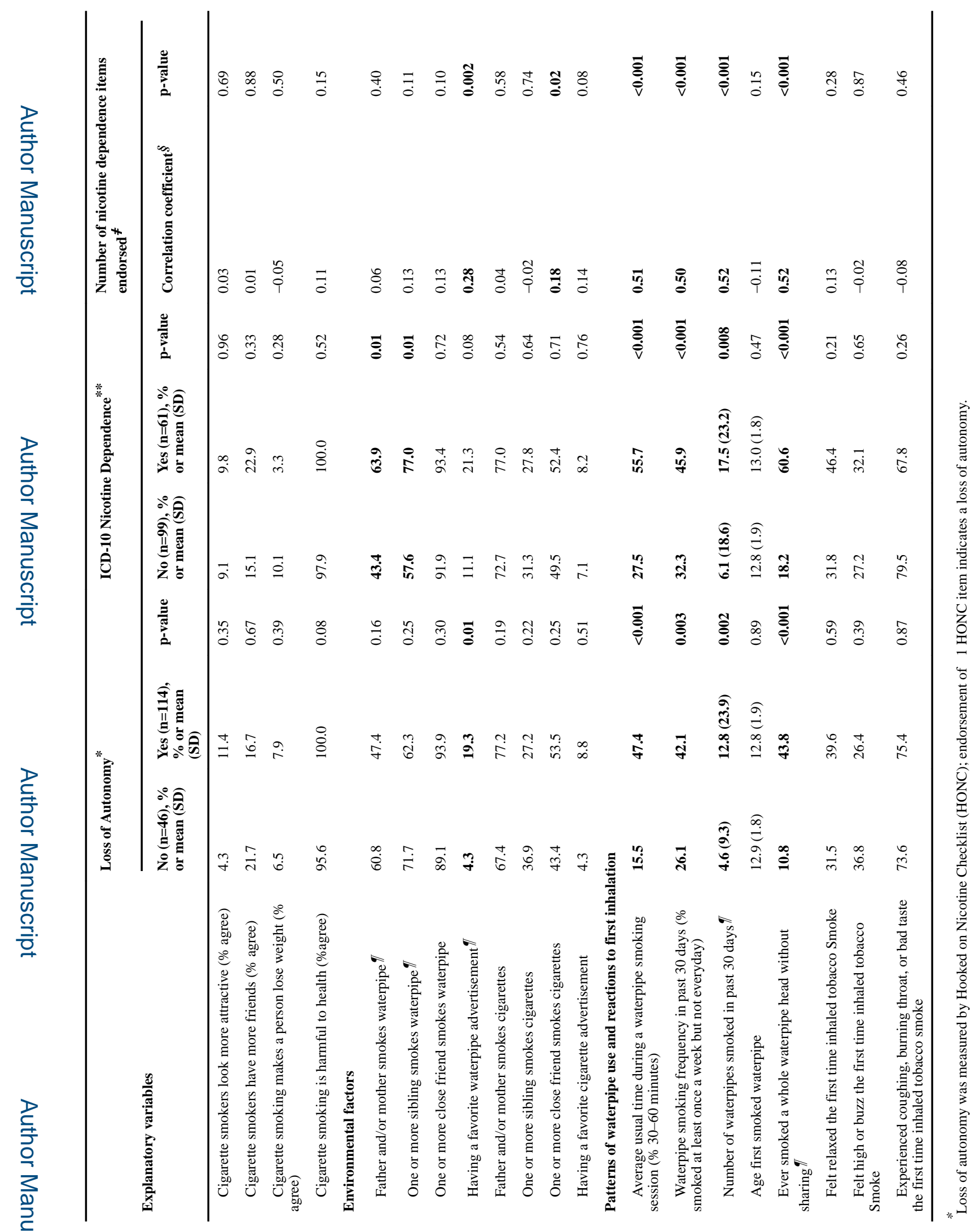

Drug Alcohol Depend. Author manuscript; available in PMC 2017 November 01. 
Bahelah et al.

Page 20

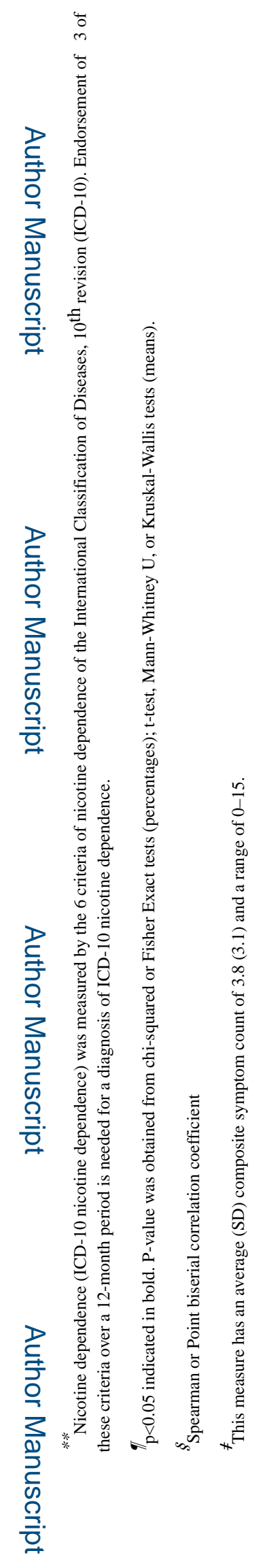

Drug Alcohol Depend. Author manuscript; available in PMC 2017 November 01. 
Bahelah et al.

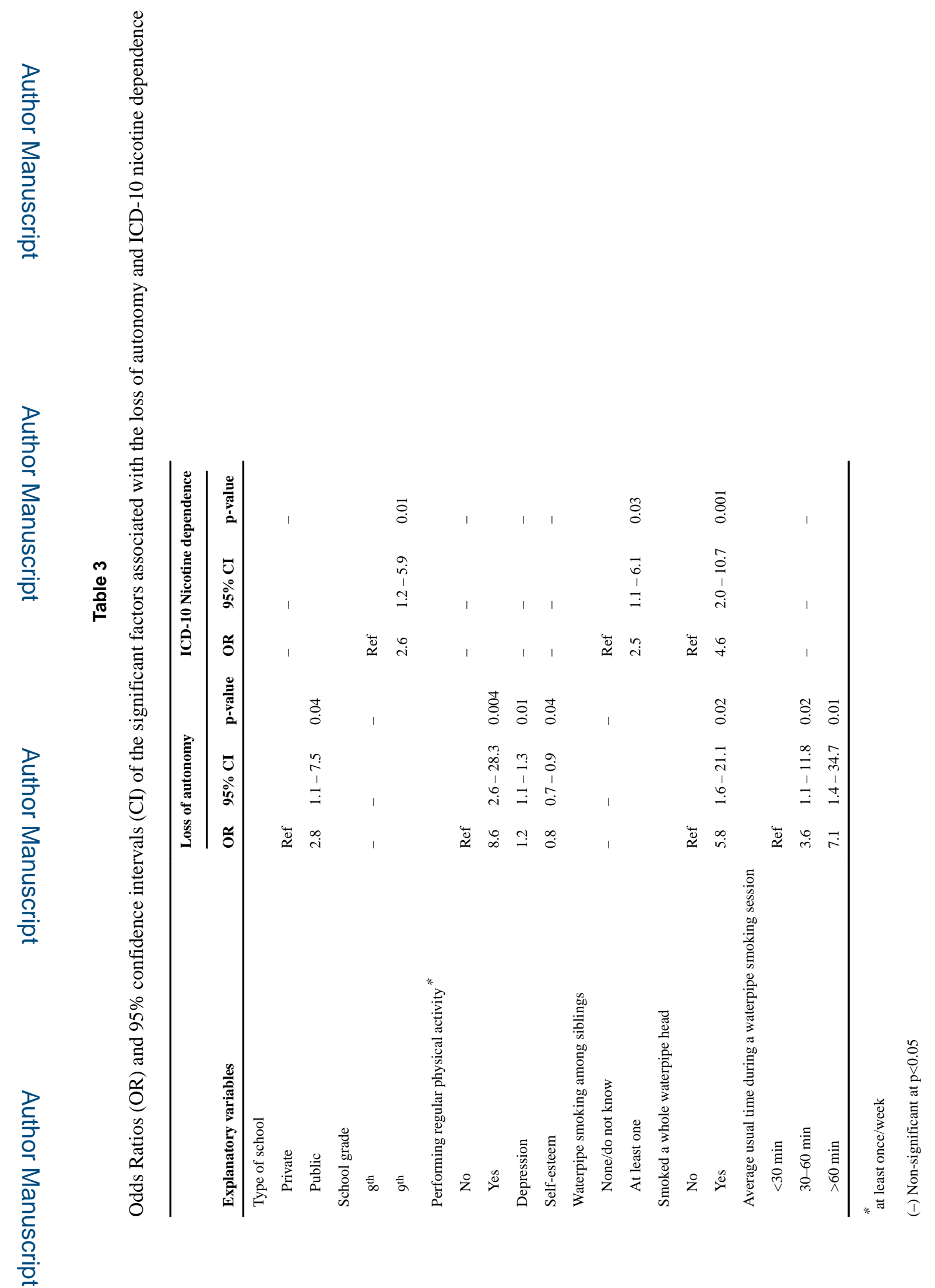

Drug Alcohol Depend. Author manuscript; available in PMC 2017 November 01. 


\section{Table 4}

Regression parameters $(b)$ and $95 \%$ confidence intervals (CI) of the significant factors associated with the number of nicotine dependence items endorsed

\begin{tabular}{llll}
\hline Explanatory variable & $\boldsymbol{b}$ & $\mathbf{9 5 \%}$ CI & p-value \\
\hline Type of school & & & \\
$\quad$ Private & Ref & & \\
$\quad$ Public & 0.22 & $0.01-0.44$ & 0.04 \\
School grade & & & \\
$\quad 8^{\text {th }}$ & Ref & & \\
$9^{\text {th }}$ & 0.31 & $0.09-0.53$ & 0.005 \\
Smoked a whole waterpipe head & & & \\
$\quad$ No & Ref & & \\
$\quad$ Yes & 0.49 & $0.26-0.72$ & $<0.001$ \\
Average usual time during a waterpipe smoking session & & & \\
$<30$ min & Ref & & \\
$30-60$ min & 0.30 & $0.02-0.57$ & 0.03 \\
$>60$ min & 0.36 & $0.05-0.68$ & 0.02 \\
Cigarette smoking is harmful to health & & & \\
Disagree & Ref & & \\
Agree & 0.28 & $0.02-0.54$ & 0.03 \\
\hline
\end{tabular}

Drug Alcohol Depend. Author manuscript; available in PMC 2017 November 01. 